\title{
Effect of education based on Pender's health promotion model on nutrition behavior of adolescent girls
}

Farideh Naserpoor ${ }^{1}$, Fereshteh Zamani-Alavijeh ${ }^{1}$, Parvin Shahri ${ }^{1}$, Amal Saki Malehi ${ }^{2}$

\author{
Journal of Research \& Health \\ Social Development \& Health Promotion \\ Research Center \\ Vol. 8, No.5, Sep \& Oct 2018 \\ Pages: $394-402$ \\ DOI: $10.29252 / j r h .8 .5 .394$ \\ Original Article
}

1. Social Determinants of Health Center Research, School of Public Health, Jundishapur University of Medical Sciences, Ahwaz, Iran

2. Department of Epidemiology and Biostatistics, School of Public Health, Jundishapur University of Medical Sciences, Ahwaz, Iran

Correspondence to: Fereshteh Zamani-Alavijeh, Department of Health Education and Promotion, School of Health, Isfahan University of Medical Sciences, Isfahan, Iran

Email: fe.zamani@gmail.com

Received: 26 Apr 2015

Accepted: 4 Sep 2015

How to cite this article: Naserpoor F, ZamaniAlavijeh F, Shahri P, Saki Malehi A. Effect of education based on Pender's health promotion model on nutrition behavior of adolescent girls. $J$ Research \& Health2018; 8(5): 394- 402

\begin{abstract}
Poor eating habits are formed and stabilized from childhood and adolescence, so, if there is no intervention to correct it, the dietary habits can be the source of health problems in the future. This study aimed to evaluate the effect of education based on Pender's health promotion model on nutritional behavior of high school girls. This study was performed on 128 adolescents (two groups of 64 students). The data collection tool was a questionnaire designed based on the Pender's health promotion model. Educational intervention consisted of four 45 to 60 minute training session for students and a training session for mothers with teaching methods of lecture, questioning and answering and group discussion. The two groups before the intervention were not significantly different in terms of demographic variables and the mean score of behavior and model constructs. But after the intervention, the mean score of healthy nutrition behaviors increased from 14.12 to 15.29 in the experimental group. The mean score of some model structures such as selfefficacy, perceived benefits and interpersonal norms in the test group significantly increased and the mean score of perceived barriers decreased significantly. But modeling structure didn't show significant changes. The results of this study focuses on the effectiveness of health promotion model in changing nutrition behaviors. An increase in the perceived benefits and self-efficacy as well as a reduction in the perceived barriers to healthy eating are the strategies that can be the basis of the programs that are designed to promote healthy behaviors in adolescents especially in the school environment.
\end{abstract}

Keywords: Adolescents, Education, Health Promotion, Nutrition

\section{Introduction}

Eating habits are a part of lifestyle and in the meantime, a dietary pattern of adolescents is one of the major public health concerns, because there is a direct link between poor diet and chronic diseases [1].

Adolescence is a period of rapid growth and maturation. The changes during this period, on the one hand, keep the young people at risk of unhealthy behaviors, Such as poor eating habits and inactivity. On the other hand, use of a healthy diet, supports the potential growth and adolescent health and reduces the risk of chronic diseases in the long term [2]. It has been proved that poor dietary habits and 
eating disorders in adolescents directly causing serious problems for these people in the future such as cardiovascular disease, diabetes, obesity, hyper lipidemia, hypertension and cancer [3].

Studies have shown that in different countries, more than 80 percent of teenagers have highrisk behaviors such as poor diet, lack of fruit and vegetable consumption to the extent necessary, and lack of physical activity. Teenagers do not consume the recommended amounts of fiber, and consumption of the breakfast, milk and milk products consumption is lower in girls than boys [4-6].

Studies also revealed that in Iran, Iranian adolescents have unhealthy diets and now they go quickly towards the Western dietary pattern included fast foods and processed (sausage, salami, pizza, etc.) [7].

90 percent of adolescents Food-performance is undesirable. More than half of adolescents consume too much salt, 48.6 percent use fast foods and 75.4 percent eat harmful snacks like chips. Poor eating habits shaped and fixed from childhood [8], and if no intervention is done in this area, the dietary habits can be the source of health problems in the future. It is estimated that only the cost of treating the type 2 diabetes as a lifestyle-related diseases will increase over total amount of \$ 192 million, by 2030. However, that may be preventing the loss of all costs and mortality with a healthy diet and exercise in the primary school life $[9,10]$.

The best solution in this area is providing intervention programs in order to change undesirable nutrition behaviors and promote good behaviors. One of these solutions in any educational program is using the models and patterns of behavior change. Using the model as a framework for educational programs can enhance the effectiveness of the program. In current study the theoretical framework that applied, was a numbers of Health Promotion Model (HPM) constructs. This model includes factors which directly or indirectly impact on health promoting behaviors. This model is used in those health behaviors framework in this study was using of some structures of health promotion model where fear and threat does not act as the main driver of behavior. This model consists of three groups of factors that influence on health behaviors, experience and personal traits, feelings and behavior specific cognitions and behavioral outcomes; Healthpromoting behavior is the final point and the outcome in HPM.

Some of the structures forming the model, included self-efficacy (Belief in yourself ability to carry out an action), perceived benefits of behavior, perceived barriers in the way of doing an act, interpersonal influences which includes norms (expectations of others) and modeling (learning by observing the behavior of others), In this model, health promoting behavior means an act which done at a specific time and has a specific context and purpose. Emotions and behavior-specific cognitions are the main motivations factors in HPM's model. These factors can be modified or altered through interventions. So they often form the core of interventions. The variables in the model HPM Included perceived benefits of action, perceived barriers to ction, perceived self-efficacy, Interpersonal and situational influences and feelings associated with their behavior [11].

Many studies have used the model of health promotion to intervene in order to increase healthy behaviors especially physical activity [12-14] But further studies based on this model in this context were the cross-sectional descriptive-analytic study. And educational intervention researches were considered less; for example Rahimi et al. used the model of Health Promotion in forecasting breakfast consumption in students [15], as well as some studies have used this model to check factors affecting self-care behaviors nutrition in patients [16,17].

Therefore, since teaching healthy behaviors especially in the early stages of life to institutionalize this behavior in children and adolescents and reduce the impact of risk factors that threaten health is so important, we should learn them healthy behavior and how to deal with unhealthy behaviors 
before getting them with unhealthy and unsafe behavior and be drawn to it. Therefore, this study aimed to investigate the effect of education based on health promotion model on the feeding behavior of high school girls in the city of Omidiyeh has been designed.

\section{Method}

This study was performed to semi experimental method on 128 female students of Omidiyeh city (Khuzestan province, Iran) in 2014. That is, using the related formulas and counting the sample loss, a total of 75 students in each group were allocated. In the end, 64 students entered to the intervention group and 64 students remained in the control group. Sampling was done by random cluster such that the three schools of all female high school of Omidiyeh city were randomly selected and then one of the high schools, as the experimental group and two other high schools were considered as the control group. Then from each of the schools, some classes were randomly selected. Inclusion criteria were having no nutritionrelated diseases, Being student in the first year of high school and filling out the written consent form.

Also, those who did not participate continuously at educational sessions were excluded. Data collection tool was the questionnaire designed based on the model of health promotion which consists of demographic information about age, body mass index, parental education and occupation and family income. Also, the questionnaire related to cognitive variables was designed using some studies [18], and includes the structures of perceived benefits of behavior, perceived barriers, self-efficacy and interpersonal influences (norms, interpersonal and modeling).

In the context of health promoting behavior, a questionnaire was used with 4 questions to assess the level of compliance healthy eating behaviors during the week includes the options; at all (any day of the week) and always (6 to 7 days a week) that the range of scores in the structure was from 4 (the highest level of respect for healthy nutrition) to 20 (lowest respect for healthy nutrition). For any of the barrier structures and self-efficacy, 8 questions with 5 point Likert scale from strongly agree to strongly disagree was used which range from 8 to 40 scores. For perceived benefits structures 7 questions was used with scores ranging from 7 to 35 .

In all structures, except perceived barriers, the higher score represents more positive impression, but in structure of perceived barriers, the higher score represents a negative one. Also, 2 questions were considered for Interpersonal norms structure and 2 questions for modeling with three choices Likert that respectively assessed the expected family (mother and friends) of students follow a healthy diet and the extent to which this behavior done by these individuals. The range of scores in the two structures were variables from 2 to 6 .

In order to assess the validity of questionnaire, the content validity was used by a panel of experts (10 experts from the fields of Health Education, and Nutrition) .

Then Content Validity Ratio (CVR) and Content Validity Index (CVI) was calculated for each item. To assess the reliability of the questionnaire, method of calculating Cronbach's alpha was used. That it rate in various structures from 0.87 to 0.80 , respectively. The steps of the intervention was so that, first, after obtaining the consent and permission from education officials and the parents of students, as well as filling out consent form by students, for the pretest and the first phase of data collection, Questionnaires were distributed among students and they were given ample and equal opportunity to complete them.

Then educational intervention consisted of 4 training session for students and a training session for mothers was held. At first, a training session with the content of healthy diet especially in adolescence, the type and amount of food intake in adolescents and the problems caused by unhealthy food consumption was held for the students. Then at the next meetings in order to intervene 
on the basis of model structures Pender using lectures, Q \& A, group discussion and the poster training was conducted so that the students were asked to express the perceived interests and barriers in observance of healthy nutrition.

Then with the help of research and scientific sources in addition to describing the benefits of healthy nutrition, especially among adolescents and girls, group discussion also took place in the form of groups of 7 to 10 people to students to find a greater understanding of the benefits and barriers to healthy eating and also the solutions provided to deal with obstacles, of course, those were related behavior and were unchangeable.

Also, in the field of self-efficacy, tried to have students be exposed to practices in order to realize his ability and work to change behavior gradually and in short-term goals, using the above teaching methods as well as strategies such as verbal persuasion, encouragement and reinforcement of healthy behavior, offering the experiences of successful vicarious learning especially among peers and classmates as well as encouragement to mastery experience of the behavior Then, in the following and in order to intervene in the structure of subjective norms and modeling, training session for 45 to 60 minutes held for mothers and in which they explained the importance and necessity of healthy eating in adolescent girls as well as emphasized the role of parents, especially mothers, in providing the correct pattern and to encourage students to adhere to a healthy diet. For the second phase of data collection, and to assess the impact of intervention, after two months, the posttest was taken.

Finally, a training session was held for students in the control group. Also, data Analysis was performed with SPSS-16 as well as paired t-tests, Chi-square test and descriptive analysis

\section{Results}

The mean age of the students in the experimental group was $14.9 \pm 0.7$ and in the control group was $15.2 \pm 0.7$. The mean body mass index was $20.8 \pm 3.5$ in the experimental group and $20.2 \pm 2.8$ in the control group. In the study conducted using statistical analysis to determine differences such as t-test for quantitative variables and chi-square test for categorical variables, no significant difference ( $p>0.05$ ) observed between groups in terms of demographic variables such as age, parental education, parental occupation and family income. And two groups in terms of these variables were similar (Table 1).

Also, as can be seen in Table 2, before the intervention, there was no significant difference between the mean behavior of healthy nutrition and model structures in two groups ( $\mathrm{p}>0.05)$.

While after intervention, there was significant difference between the mean scores for most of the variables in two groups (Table 1). Thus, the mean score of healthy nutrition in the experimental group had a significant increase (Table 1).

Mean scores on perceived self-efficacy, perceived benefits, and interpersonal norms increased, and the mean score of perceived barriers had a significant reduction $(p<0.05)$. Paired t-test showed that there are significant differences between the more variables involved, except the modeling in the experimental group, before and after the intervention $(p<0.05)$ (Table 2$)$.

\section{Discussion}

This study showed that educational program based on the health promotion model can result healthy nutrition to be improved and promoted. So far, HPM in many studies has been used for prediction of factors associated with health behaviors also to change those behaviors.

For example, the model of health promotion is used in studies such as the prediction of quality of life in female adolescents [19], prediction of factors affecting oral health [20], physical activity behavior change $[12,13]$ and changes in breakfast eating behaviors [3]. And all these studies emphasized on the effectiveness of this model. In this regard, the present study was designed in order to correct 
Table 1 Comparison of demographic variables between intervention and control groups

\begin{tabular}{|c|c|c|c|c|c|c|}
\hline \multirow{2}{*}{\multicolumn{2}{|c|}{ Demographic characteristics }} & \multicolumn{2}{|c|}{ Intervention } & \multicolumn{2}{|c|}{ Control } & \multirow{2}{*}{$\begin{array}{c}\mathrm{p} \text {-value } \\
\text { chi-square test }\end{array}$} \\
\hline & & $\mathrm{n}$ & $\%$ & $\mathrm{n}$ & $\%$ & \\
\hline \multirow{4}{*}{ Occupation of father } & Employee & 12 & 18.8 & 11 & 17.2 & \multirow{4}{*}{0.760} \\
\hline & Casual labourer & 19 & 29.6 & 22 & 34.37 & \\
\hline & Self-employed & 30 & 46.9 & 26 & 40.62 & \\
\hline & Retired & 3 & 4.7 & 5 & 7.81 & \\
\hline \multirow{3}{*}{ Occupation of mother } & House duties & 63 & 98.4 & 60 & 93.75 & \multirow{3}{*}{0.082} \\
\hline & Employee & 1 & 1.6 & --- & ----- & \\
\hline & Self-employed & --- & ---- & 4 & 6.25 & \\
\hline \multirow{4}{*}{$\begin{array}{l}\text { Father's education } \\
\text { level }\end{array}$} & Illiterate & 5 & 7.8 & 1 & 1.56 & \multirow{4}{*}{0.051} \\
\hline & 1th -6 th(grade) & 25 & 39.1 & 18 & 28.11 & \\
\hline & 7th -11 th (grade) & 18 & 28.1 & 15 & 23.43 & \\
\hline & $\geq 12$ th $($ grade $)$ & 16 & 25 & 30 & 46.9 & \\
\hline \multirow{4}{*}{$\begin{array}{l}\text { Mother's education } \\
\text { level }\end{array}$} & Illiterate & 9 & 14.1 & 4 & 6.25 & \multirow{4}{*}{0.079} \\
\hline & 1th -6 th (grade) & 34 & 53.1 & 30 & 46.87 & \\
\hline & 7th -11 th (grade) & 18 & 28.1 & 20 & 31.25 & \\
\hline & $\geq 12$ th $($ grade $)$ & 3 & 4.7 & 10 & 15.63 & \\
\hline \multirow{4}{*}{ Family income } & $<300$ Hundred Rials & 17 & 26.6 & 9 & 14.07 & \multirow{4}{*}{0.214} \\
\hline & 300-500 Hundred Rials & 18 & 28.1 & 17 & 26.56 & \\
\hline & $\begin{array}{l}\text { 500Hundred Rials- 10milion } \\
\text { Rials }\end{array}$ & 24 & 37.5 & 28 & 43.75 & \\
\hline & $>10$ milion Rials & 5 & 7.8 & 10 & 15.62 & \\
\hline
\end{tabular}

Table 2 Comparison of mean (standard deviation) Pender's health promotion model constructs related to healthy nutrition behavior in the intervention and control groups before and after the intervention

\begin{tabular}{|c|c|c|c|c|}
\hline \multirow{2}{*}{ Structures } & \multirow{2}{*}{ Time } & Intervention group & Control group & \multirow{2}{*}{$\mathrm{p}^{* *}$} \\
\hline & & $\mathrm{m} \pm \mathrm{sd}$ & $\mathrm{m} \pm \mathrm{sd}$ & \\
\hline \multirow{3}{*}{$\begin{array}{l}\text { Healthy nutrition } \\
\text { behavior }\end{array}$} & Before intervention & $14.12 \pm 3.1$ & $13.45 \pm 2.7$ & 0.202 \\
\hline & After intervention & $15.29 \pm 2.4$ & $12 \pm 3.48$ & $<0.001$ \\
\hline & $\mathrm{p}^{*}$ & $<0.001$ & 0.01 & \\
\hline \multirow{3}{*}{ Self-efficacy } & Before intervention & $25.64 \pm 5.2$ & $26.59 \pm 4.8$ & -1.072 \\
\hline & After intervention & $28.7 \pm 4.5$ & $26.45 \pm 6$ & 2.447 \\
\hline & $\mathrm{p}^{*}$ & $<0.001$ & 0.816 & \\
\hline \multirow{3}{*}{ Perceived benefits } & Before intervention & $29.51 \pm 3.4$ & $30.12 \pm 4.7$ & 0.409 \\
\hline & After intervention & $30.62 \pm 3.2$ & $28.62 \pm 5.1$ & 0.030 \\
\hline & $\mathrm{p}^{*}$ & 0.002 & 0.001 & \\
\hline \multirow{3}{*}{ Perceived barriers } & Before intervention & $29.65 \pm 4.9$ & $29.38 \pm 5.5$ & 0.769 \\
\hline & After intervention & $27.5 \pm 4.1$ & $30.01 \pm 5.05$ & 0.003 \\
\hline & $\mathrm{p}^{*}$ & $<0.001$ & 0.421 & \\
\hline \multirow{3}{*}{ Interpersonal norms } & Before intervention & $4.8 \pm 0.9$ & $4.8 \pm 0.9$ & 0.651 \\
\hline & After intervention & $4.9 \pm 0.8$ & $4.8 \pm 0.9$ & 0.08 \\
\hline & $\mathrm{p}^{*}$ & 0.009 & 0.808 & \\
\hline \multirow{3}{*}{ Modeling } & Before intervention & $4.6 \pm 0.9$ & $4.3 \pm 1$ & 0.656 \\
\hline & After intervention & $4.5 \pm 0.8$ & $4.3 \pm 1$ & 0.147 \\
\hline & $\mathrm{p}^{*}$ & 0.912 & 0.343 & \\
\hline
\end{tabular}

"p-value of Paired-Samples T test

** p-value of Independent-Samples T test 
and change the healthy nutrition behavior based on some structures of HPM model.

In this study the average score of healthy eating behavior increased. Given that the results of the analysis, before intervention there was no significant difference between the two groups, therefore increase in scores of healthy nutrition in test group attributed to the intervention. Many studies have shown that nutrition education in schools is one of the factor influencing the eating behavior of students [4,21]. In a review article [4] it has been stated that nutrition education program should target, in addition to knowledge, mediators of behavioral change and social cognitive factors. Current study emphasized on change in feeding behavior through intervention based on some of these factors.

In this research, there was a significant increase in perceived self-efficacy after intervention in the experimental group. In several studies, this structure always has been associated with change of diet. And the changes in self efficacy can lead to changes in feeding behavior. In similarity with other studies [22,15] that have shown perceived benefits or a positive attitude to a behavior has a significant impact on changing behavior, in this study, educational program impact on the perceived benefits was positive. About the structure of perceived barriers the result was similar with previous research results [23]. And after the educational intervention, scores of perceived barriers to healthy eating in the experimental group had a significant decrease.

It should be noted that before intervention, test and control groups had no difference in terms of perceived barriers and other model factors so, , the difference in this structure could be attributed to the impact of educational intervention. However, in an educational intervention which has been performed to reduce the fat in the diet of females [24], education has no effect on social protection, Self-efficacy, benefits and barriers of the students. And this intervention even had a negative effect on the perceived barriers.

These differences in results can be primarily attributed to differences in objective of the studies, because this study only dealt with reducing high-fat foods in the diet of girls. And perhaps these structures may not be effective, in the case of changing targeted behavior. In the second place, it should be noted that in comparison with adults, adolescents more react to the mediate temptation and the influence of the environment on the behavior of adolescents is even more than psychological traits [25].

Theory of Pender expressed, if people have positive modeling and be supported by family members, is more likely to show a certain behavior, but in this study, after intervention, there was no significant difference between scores of interpersonal norms and modeling in two groups. And structure of modeling, after intervention, had not significantly change. These findings are in contrast to studies that emphasize the role and importance of family and friends to adopt healthy eating behaviors [26]. modeling has been identified in many studies as a potential factor in changing nutritional behavior [27].

But despite most of non-experimental studies have continuously introduced interpersonal influences and modeling as the factors of change of nutritional behavior, interventional studies to a lesser extent support these structures [22].

For example, in a study that carried out to assess eating breakfast behavior, there was no significant correlation between interpersonal influences structures and eating behavior. In the other words, there was no significant difference between modeling role and interpersonal norms in people who had normal nutritional behavior and people with unhealthy behaviors [15].

In this regard, it must be said although education has a considerable impact on changing the behavior of students but even high quality education is not enough for creating healthy eating behavior. And to achieve a sustainable result, the environment must be improved, but sometimes it has been observed that environment not only have no 
a positive impact but encourage unhealthy behaviors, too [21].

In a qualitative study [28], most families believed that wrong modeling in society is the major causes of unhealthy eating habits of adolescents. As previously mentioned, environmental influences on adolescents even can outshine psychological traits. This is more especially in today's world in which information resources becomes broader every day.

On the other hand, some studies have shown that foods in humans at different ages are significantly different. For example, at an early age, dependence of children on parents is more so that eating behavior is often influenced by parents, but in adolescence and the transition from childhood to adulthood most people are trying to reduce their dependence on parents. So, feeding behavior in adolescents probably less influenced by their parents [25].

\section{Conclusion}

The results showed that nutrition education based on the model of health promotion can be effective in changing behavior. And proper training can increase healthy eating behaviors among teen girls with emphasis on increasing self-efficacy, perceived benefits and reducing barriers to follow a healthy diet. It should be considered that to influence nutrition behavior in adolescent girls the designed training programs would increase understanding of adolescent girls of the benefits of healthy eating behaviors as well as increasing understanding of their abilities to overcome obstacles in respect of healthy eating that is the same structures of perceived self-efficacy, and could have a significant effect on the promotion of healthy nutrition.

Intervention on the individual effects significantly increases this behavior. The current study, revealed that family and friends grow more expectation for teenagers to consider nutritional healthy behaviors in intervention group. But we should not forget that this behavior is associated to many factors. For example, the many families believe that lack of appropriate modeling in community as well as the higher cost of healthy foods are the most important factors that affects nutritional behavior.[25]

Therefore, future interventions should consider this issue and the programs would focus on different aspects in the context of promoting healthy eating behaviors in adolescents. There were limitations in the design and implementation of this study too. Data collection tool was a self-report questionnaire. Therefore despite the fact that it couldn't cover all factors affecting the nutrition, students' answers may also have been affected by the onslaught of social utility. In the field of implementation, we faced with some problems due to the target group in achieving the right time and place for education, as well as access to parents was another problem. Of course, sincere cooperation of school authorities was solved many of these problems.

\section{Acknowledgements}

This article is a part of the thesis of the first author in Ahvaz university of medical sciences. Hereby, we thank the authorities concerned of the university, also all those who helped us at different stages of this study, especially education authorities and esteemed managers of Omidiyeh high schools.

\section{Contribution}

Study design: FN, FZA

Data collection and analysis: ASM. FN

Manuscript preparation: FN, FZA, PSh

\section{Conflict of Interest}

No conflict of interest has been expressed by the authors.

\section{Funding}

The author (s) received no financial support for the research, authorship and/or publication of this article.

\section{References}

1- Pinho LD, Silveira MF, Botelho AC, Caldeira AP. Identification of dietary patterns of adolescents attending public schools. J Pediate2014; 90(3): 267-72. 
2- Lai Yeung WL. Gender perspectives on adolescent eating behaviors: a study on the eating attitudes and behaviors of junior secondary students in Hong Kong. $J$ Nutr Educ Behav2010; 42(4): 250-8.

3- Dehdari T, Khezeli M, Bakhtiyari M, Nilsaz M. Health education interventions on student nutrition: a systematic review. Journal of Health2012; 3(3) :62-72.

4- Kelly NR, Mazzeo SE, Bean MK. Systematic review of dietary interventions with college students: directions for future research and practice. J Nutr Educ Behav2013; 45(4): 304-13.

5- Fenner AA, Straker LM, Davis MC, Hagger MS. Theoretical underpinnings of a need-supportive intervention to address sustained healthy lifestyle changes in overweight and obese adolescents. Psychol Sport Exerc2013; 14: 819-29

6- Musaiger A, Kalam F. Dietary habits and lifestyle among adolescents in Damascus, Syria. Ann Agric Environ Med2014; 21(2): 416-9.

7-Amini K, Mojtahedi SY, Mousaiefard M. Consumption of fruits, vegetables, dairy products and meat among high school students in Zanjan Province, Iran. Journal of School of Public Health and Institute of Public Health Research2009; 7(2): 25-39.

8- Pirzadeh A, Hazavhei MM, Entezari MH, Hasanzadeh A. The effect of educational program on nutritional knowledge and behavior of middle school female second graders in Isfahan in 2009. Iranian Journal of Medical Education2011; 11(2): 94-102.

9- Mainbolagh BL, Rakhshani F, Zareban I, Montazerifar F, Sivaki HA, Parvizi Z. The effect of peer education based on health belief model on nutrition behaviors in primary school boys. Journal of Research \& Health Social Development \& Health Promotion Research Center2012; 2(2): 214-25.

10- Abood DR, Black DR, Feral D. Nutrition education worksite intervention for university staff: application of the health belief model. J Nutr Educ Behav2003; 35(5): 260-7.

11- Alligood MR. Introduction to nursing theory: its history, significance, and analysis. In Marrincr Tomcy A, Alligood MR, eds. Nursing theorists and their work; 2006. pp: 3-15.

12- Taymoori P, Niknami S, Berry T, Lubans D, Ghofranipour F, Kazemnejad A. A school-based randomized controlled trial to improve physical activity among Iranian high school girls. Int J Behav Nutr Phys Act2008; 5(1): 18.

13- Karimi M, Eshrati B. The effect of health promotion model-based training on promoting students' physical activity. Journal of Kermanshah University of Medical Sciences2012; 16(3): 192-200.

14- Sanaeinasab H, Saffari M, Pakpour AH, Nazeri M, Piper CN. A model-based educational intervention to increase physical activity among Iranian adolescents. J Pediatr2012; 88(5): 430-8.

15- Rahimi T, Dehdari T, Ariaeian N, Gohari M. Survey of breakfast consumption status and its predictors among Qom students based on the Pender's health promotion model constructs. Iranian Journal of Nutrition Sciences \& Food Technology2012; 7(2): 75-84

16- Mohebi S, Azadbakht L, Feyzi A, Hozoori M, Kamran A, Sharifiard G. Educational needs of women with metabolic syndrome on healthy nutrition in Isfahan: application of health promotion model. Journal of health2013; 4(2): 165-79.

17- Kamran A, Azadbakht L, Sharifirad G, Mahaki B, Mohebi S. The relationship between blood pressure and the structures of Pender's health promotion model in rural hypertensive patients. $J$ Educ Health Promot2015; 4: 29-34.

18- Dini Talatappeh H, Tavakoli H, Rahmati Najarkolaei F, Dabbagh Moghadam A, Khoshdel A. Knowledge, beliefs and behavior of food consumption among students of Military University: The application of health belief model (HBM). Iranian Journal of Military Medicine2012; 14(3): 192-9.

19- Mohamadian H, Eftekhar Ardebili H, Rahimi Foroushani A, Taghdisi M, Shojaiezade D. Evaluation of Pender's health promotion model for predicting adolescent girls' quality of life. Journal of School of Public Health and Institute of Public Health Research2011; 8(4): 1-13.

20- Bahmanpour K, Nouri R, Nadrian H, Salehi B. Determinants of oral health behavior among high school students in Marivan County, Iran based on the Pender's Health Promotion Model. sjsph. 2011; 9 (2) :93-106

21.Zamani Alavijeh F, Faghihzadeh S, Sadeghi F. A Application of the Health Belief Model for Unhealthy Eating Prevention among Primary School Children in Arak / Iran (2004-2005). Journal of Kermanshah University of Medical Sciences 2008;11(4).

22.Shaikh AR, Yaroch AL, Nebeling L, Yeh M-C, Resnicow K. Psychosocial predictors of fruit and vegetable consumption in adults: A review of the literature. Am J Prev Med 2008;34(6):535-543.

23. Moore MM, Robinson JC, Rachel MM, Boss BJ. Barriers to Physical Activity and Healthy Diet Among Children Ages 6 Through 13 in a Mississippi Elementary School. J Pediatr Nurs 2014;29(1):74-82. 24.Haerens L, Cerin E, Deforche B, Maes L, De Bourdeaudhuij I. Explaining the effects of a 1-year intervention promoting a low fat diet in adolescent girls: a mediation analysis.

Int J Behav Nutr Phys Act 2007;4(1):55.

25.Baranowski T, Cullen KW, Baranowski J. Psychosocial correlates of dietary intake: advancing 
dietary intervention. Annu Rev Nutr 1999;19(1):17-40. 26.Cheng TS, Tse LA, Yu ITS, Griffiths S. Children's Perceptions of Parental Attitude Affecting Breakfast Skipping in Primary Sixth-Grade Students.

J Sch Health 2008;78(4):203-208.

27.Cerin E, Barnett A, Baranowski T. Testing theories of dietary behavior change in youth using the mediating variable model with intervention programs. J Nutr Educ Behav 2009;41(5):309-318.

28.Ramezani Tehrani F, Farahmand M, Amiri P, Paikari N, Azizi F. Women's Perception Regarding to Healthy Nutrition Inhibitors: a Qualitative Research in Tehran Lipid and Glucose Study (TLGS). Iranian Journal of Endocrinology \& Metabolism 2011;13(1):48-57.

\footnotetext{
Copyright $(\mathrm{C} 2016$ ASP Ins. This open-access article is published under the terms of the Creative Commons Attribution-NonCommercial 4.0 International License which permits Share (copy and redistribute the material in any medium or format) and Adapt (remix, transform, and build upon the material) under the Attribution-NonCommercial terms.
} 